\title{
Effects of Pre-inhalation of Salbutamol on Cough Reflex Induced by Sufentanil
}

\author{
Jie Li and $\mathrm{Kai} \mathrm{Li}^{*}$ \\ Department of Anesthesiology, China-Japan Union Hospital, Jilin University, Changchun 130033, China \\ ${ }^{*}$ Corresponding author
}

\begin{abstract}
Purposes: This study was designed to evaluate the effect of pre-inhalation of salbutamol aerosol(200 $\mu \mathrm{g})$ and injection speed on sufentanil-induced cough. Methods: 160 patients aged 25-62yr, ASA I - II, scheduled for various elective surgical procedures under general anesthesia were randomly allocated into four groups of 40 each. Group II, IV served as control received saline aerosol, and Group I, III received a preinhalation of one metered aerosol puff of salbutamol $(200 \mu \mathrm{g})$ $10 \mathrm{~min}$ prior to intravenous injection of sufentanil. Sufentanil $0.5 \mu \mathrm{g} / \mathrm{kg}$ was administered within $3 \mathrm{~s}$ in Group I, II, or over 30s in Group III, IV. The concentration of sufentanil was $10 \mu \mathrm{g} / \mathrm{ml}$. The incidences and severity of cough that occurred within $1 \mathrm{~min}$ after the injection of sufentanil were recorded, the HR and SBP at pre-anesthetic(T1), 5 minutes after inhalation(T2), and 1 minute after injecting sufentanil (T3) were also recorded. Results: The incidence of cough in Group I, $\operatorname{IV}(\mathbf{1 0 \%}, \mathbf{1 2 . 5 \% )}$ were less than Group II $(37.5 \%)(p<0.05)$; The incidence of cough in Group III $(2.5 \%)$ was significantly lower Group II $(\mathbf{p}<0.01)$. The highest non-invasive blood (NIBP) and heart rate (HR) were at T3 timepoint in Group II $(\mathbf{p}<0.05)$. Conclusions: The pre-inhalation of salbutamol $(200 \mu \mathrm{g})$ combined with a prolonged injection time significantly reduced the incidence of sufentanil-induced.
\end{abstract}

Keywords-salbutamol; sufentanil; cough; pre-inhalation

\section{INTRODUCTION}

This Opioid drugs have been widely used in clinical anesthesia for their strong analgesic properties, short duration of action, and cardiovascular stability. Sufentanil is a synthetic opioid analgesic drug approximately five to 10 times more potent than its parent drug, fentanyl. However, it is commonly accompanied with opioid-induced cough, respiratory depression, and postoperative nausea and vomiting during induction of general anesthesia[1]. Previous studies have found that the incidence of fentanyl-induced cough varies between $2.7 \%$ and $65 \%[2,3]$. The tussive effect of sufentanil is usually transient and self-limited for most patients. Yet this phenomenon may be undesirable in patients with some coexisting diseases including increased intracranial pressure, open eye injury, dissecting aortic aneurysm, pneumothorax or reactive airway disease. Severe complications and unpleasant experience should not be ignored. Prevention of sufentanilinduced cough in such situations is of paramount importance. Many researches on this topic have been conducted to suppress opioid-induced cough. However, their side effects and slow onset time limit their clinical use. Salbutamol, a selective $\beta 2$-adrenergic bronchodilator, administered via a jet nebulizer, is used routinely in the management of bronchospasm. Therefore, we postulated that prior inhalation of bronchodilator prevents the bronchospasm induced by coughing. In this double-blind, randomized, and placebocontrolled study, we investigate the effect of pre-inhalation of salbutamol $(200 \mu \mathrm{g})$ combined with slow injection of sufentanil on cough caused by sufentanil during anesthetic induction.

\section{MATERIALS AND METHODS}

\section{A. Participants}

A total of 160 patients scheduled for elective surgery under general anesthesia participated in the study. Included study participants were aged 25-53 years, with an American Society of Anesthesiologists (ASA) physical status classification of III. Exclusion criteria included: a history of smoking, upper respiratory tract injection in the previous two weeks, asthma, hypertension, diabetes, chronic cough, or medication with angiotensin-converting enzyme inhibitors. No premedication was administered.

\section{B. Anesthesia and Research Procedure}

On arrival in the operating room, venous access was established on the dorsum of the non-dominate hand, electrocardiogram, non-invasive arterial blood pressure, and pulse oximetry were applied. Oxygen administration was commenced to each patient via a facial mask. The patients were randomly allocated into four groups of 40 each in a randomized and double-blinded fashion. The randomizations results were generated by computer whilst patients and observers were blind to the groups. All patients were inhaled with one metered aerosol puff of salbutamol $(200 \mu \mathrm{g})$ (Group I , III )or an equal volume of $0.9 \%$ normal saline aerosol( II, IV) $10 \mathrm{~min}$ prior to intravenous injection of sufentanil. The concentration of sufentanil was diluted from $50 \mu \mathrm{g} / \mathrm{ml}$ to $10 \mu \mathrm{g} / \mathrm{ml}$ with $0.9 \%$ normal saline. Sufentanil $0.5 \mu \mathrm{g} / \mathrm{kg}$ was administered within $3 \mathrm{~s}$ in Group I, II, or over 30s in Group III, IV. An observer who was blind to the group recorded the incidence and severity of cough that occurred within $1 \mathrm{~min}$ after the injection of sufentanil. The severity of coughing was graded based on the number of episodes of cough in $2 \mathrm{~min}$ after the end of injection: no(0), mild(1-2), moderate(3-4), severe $(>5)$ [4]. Induction of anesthesia was conducted 2 minutes after injection with midazolam $0.1 \mathrm{mg} / \mathrm{kg}$, propofol $1.5 \mathrm{mg} / \mathrm{kg}$, rocuronium $1 \mathrm{mg} / \mathrm{kg}$, and endotracheal intubation was performed. Systolic blood pressure and heart rate were 
recorded before anesthesia(T1),5 minutes after inhalation(T2), and 1 minute after the administration of sufentanil(T3). Other side effects were also recorded after the injection of sufentanil. The patients received a facial mask-assisted ventilation by supporting the chin when their oxygen saturation less than $95 \%$.

\section{Statistical Analyses}

Measurement data were expressed as mean \pm standard deviation(SD). All statistical operation was performed using SPSS 13.0 for windows. One-way analysis of variance was used between two groups. Categorical data were analyzed using the Chi-squared test. A P value of $<0.05$ was considered statistically significant.

\section{RESULTS}

The data of age and weight did not differ significantly among the four groups. ( see Table 1)

Any episode of cough was classified as coughing. Four, fifteens, one and five patients $(10 \%, 37.5 \%, 2.5 \%, 12.5 \%)$ coughed in Group I, II, III, IV, respectively. Occurrence of cough in Group I, IV was less than Group II $(\mathrm{p}<0.05)$. Occurrence of cough in Group III was significantly lower Group II $(\mathrm{p}<0.01)$. ( see Fig 1 and Table 2 )

The systolic blood pressure and heart rate readings did not differ significantly at T1 andT2 among the $\operatorname{groups}(\mathrm{p}<0.05)$, whereas an increase was found in Group II at T3(p>0.05) (see Table 3 and Table 4).

TABLE I. DEMOGRAPHic DATA AMONG The Four Groups $(\bar{x} \pm s)$

\begin{tabular}{|c|c|c|c|c|}
\hline Group & \multicolumn{1}{|l|}{$\mathbf{n}$} & Gender(M/F) & Age(years) & Weight(kg) \\
\hline I & 40 & $23 / 17$ & $40.2 \pm 12.1$ & $60.1 \pm 11.0$ \\
\hline II & 40 & $21 / 19$ & $41.1 \pm 10.2$ & $61.1 \pm 10.5$ \\
\hline III & 40 & $25 / 15$ & $39.1 \pm 11.2$ & $62.2 \pm 9.8$ \\
\hline IV & 40 & $22 / 18$ & $41.5 \pm 9.8$ & $60.5 \pm 10.9$ \\
\hline
\end{tabular}

TABLE II. INCIDENCE AND SEVERITY OF COUGH AMONG PATIENTS IN FOUR GROUPS

\begin{tabular}{|c|c|c|c|c|c|}
\hline \multirow{2}{*}{ Group } & \multirow{2}{*}{$\mathbf{n}$} & \multicolumn{3}{|c|}{ Incidence of cough } & \multirow{2}{*}{ total } \\
\hline & & \multicolumn{3}{|c|}{$\begin{array}{c}\text { No Mild Moderate } \\
\text { Severe }\end{array}$} & \\
\hline I & 40 & 362 & 1 & 1 & $4(10 \%) *$ \\
\hline II & 40 & 257 & 5 & 3 & $15(37.5 \%)$ \\
\hline III & 40 & 391 & 0 & 0 & $1(2.5 \%) * *$ \\
\hline IV & 40 & 353 & 1 & 1 & $5(12.5 \%) *$ \\
\hline
\end{tabular}

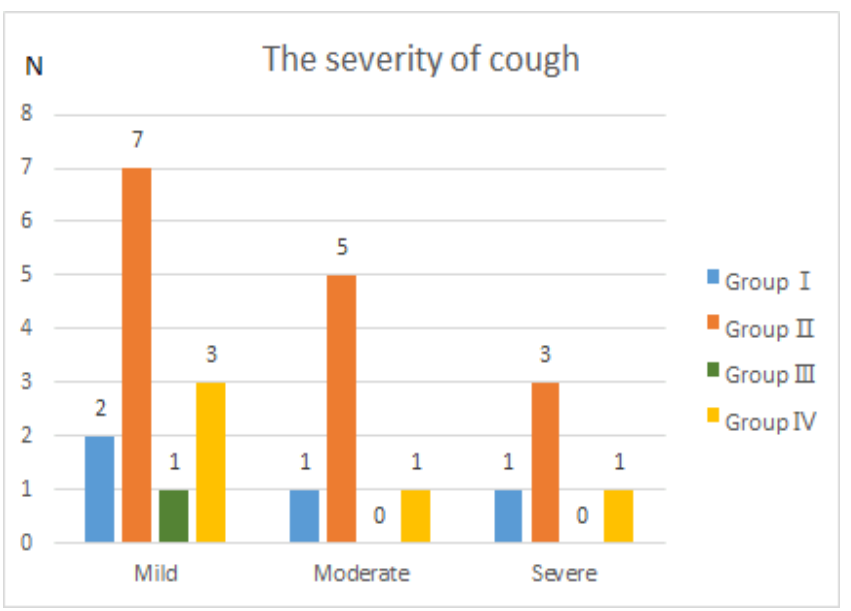

FIGURE I. INCIDENCE AND SEVERITY OF COUGH AMONG PATIENTS IN FOUR GROUPS

TABLE III. CHANGES IN SYSTOLIC BLOOD PRESSURE（MMG $\bar{x} \pm s$ )

\begin{tabular}{|c|c|c|c|}
\hline Group & T1 & T2 & T3 \\
\hline I & $117.3 \pm 13.1$ & $118.4 \pm 13.2$ & $122.5 \pm 12.1$ \\
\hline II & $120.4 \pm 11.2$ & $121.5 \pm 12.1$ & $140.7 \pm 13.5 *$ \\
\hline III & $118.9 \pm 10.6$ & $120.5 \pm 12.5$ & $116.2 \pm 12.3$ \\
\hline IV & $120.6 \pm 12.1$ & $118.5 \pm 14.1$ & $118.7 \pm 14.5$ \\
\hline
\end{tabular}

TABLE IV. Changes IN HEART RATE (BPM $\bar{x} \pm s$ )

\begin{tabular}{|c|c|c|c|}
\hline Group & T1 & T2 & T3 \\
\hline I & $79.2 \pm 20.2$ & $78.3 \pm 17.9$ & $76.7 \pm 18.1$ \\
\hline II & $80.1 \pm 18.1$ & $79.5 \pm 17.1$ & $99.8 \pm 20.1^{*}$ \\
\hline III & $82.3 \pm 16.2$ & $80.3 \pm 16.9$ & $72.6 \pm 17.6$ \\
\hline IV & $80.9 \pm 17.9$ & $81.1 \pm 17.7$ & $78.8 \pm 18.3$ \\
\hline
\end{tabular}

IV. Discussion

Salbutamol is a short-acting $\beta_{2}$ adrenergic receptor agonist which works by causing airway smooth muscles to relax. It has been used to relieve bronchoconstriction or bronchospasm in the operating room for many decades. The current study found that the incidence of cough was lower in patients inhaled salbutamol than those inhaled normal saline during general anesthesia induction. Above all, the incidence of cough was the lowest in patients who inhaled salbutamol and received sufentanil over $30 \mathrm{~s}$. The highest HR and NBP values were also higher in Group II than those in other groups after sufentanil administration, and the high values were still within a safe range.

Sufentanil, a potent synthetic opioid derived from phenylpiperidine, is primarily administered for its analgesic effect especially prior to induction of anesthesia. As any other opioid, the cough is an important side effect during general anesthesia induction. However, this phenomenon is complex with varying degrees in the reports. $[4,5]$ The cough can be 
transient, benign and self-limiting for most patients, but at times it can cause life-threatening in patients who have cerebral aneurysms. Several pharmacological interventions and other approaches have been conducted to relieve sufentanil-inducing coughing, but the side effects limit their widespread use and the current methods are not satisfactory[5, $6]$.

The mechanisms of opioid-induced cough are not well understood but several theories have been implicated. Cough is a well-integrated reflex resulting from mechanical and chemical stimulations of sensory receptors. The most likely receptors are rapidly adapting pulmonary stretch receptors (RARs) with small diameter A Delta myelinated fibers and the pulmonary and bronchial C-fiber receptors with nonmyelinated afferents. The RARs are sensitive to cough and all the mechanical and chemical stimuli that lead to cough. The rapidly adapting receptors innervating the mucosa of the proximal tracheobronchial airway can be stimulated by fentanyl causing bronchoconstriction [7]. Bronchoconstriction can sensitise the cough arises from stimulation of rapidly adapting airway receptors [8]. Lui et al. [9] found that fentanyl-induced cough was related to bronchoconstriction and it could be suppressed by inhaled $\beta 2$-adrenergic bronchodilator terbutaline. Anil Agarwal et al. [10]study showed that a metered dose of salbutamol significantly reduced the incidence of cough evoked by iv bolus of 2 $\mu \mathrm{g} \cdot \mathrm{kg}-1$ fentany. Salbutamol inhalation prior to induction of anesthesia caused bronchodilation and was an effective antitussive agent both in normal and asthmatic patients. In 2004 Lin et al.[11] reported that iv ephedrine at a dose of $5 \mathrm{mg}$ was effective in decreasing fentanyl-induced cough. Nonetheless, ephedrine works by turning on $\alpha$ and $\beta$ adrenergic receptors and it may cause cardiovascular stimulating effects. The inhalation of salbutamol can be used in patients who have severe hypertension safely without inducing dramatic hemodynamic changes. In addition, A Delta fibers respond to acid stimulation to evoke cough [12]. The main mechanism of citric acid-induced bronchoconstriction is due to the release of tachykinins after activation of sensory nerves[13]. A study by Belvisi et al. [14]demonstrated that $\beta 2$-adrenoceptor agonists were antitussive, and this property occurred due to a direct inhibition of sensory nerve activation. Therefore, $\beta 2$-agonist alleviated the cough reflex induced by capsaicin and citric acid in sufentanil injection solutions. Other possible mechanisms proposed to explain this type of cough are: (a) the dualism of opioid receptor[15];(b) the stimulation of stretch receptors of the trachea and bronchial tree[16];(c) the histamine releasing from the lung mast cells[17];(d) the reduced chest wall compliance and the sudden adduction of vocal cords originating from sufentanil-induced laryngeal muscle rigidity $[6,18]$

The occurrence of cough was significantly reduced in Group III. Yu et al.[19]showed that a prolonged injection time eliminated fentanyl-induced cough. They explained that a longer injection time resulting in a smaller peak concentration from the pharmacokinetic point of view. In another study, Lin et al. [20]showed that the incidence of evoked cough decreased to $1.3 \%$ for an injection time of 30 seconds.
In conclusion, our results show that the inhalation of

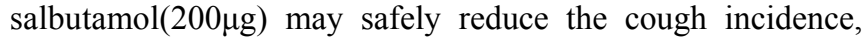
and the pre-inhalation of salbutamol $(200 \mu \mathrm{g})$ combined with a prolonged injection time eliminate the cough induced by sufentanil $(0.5 \mu \mathrm{g} / \mathrm{kg})$.

\section{REFERENCES}

[1] Shen, J., et al., Effect of equivalent doses of fentanyl, sufentanil, and remifentanil on the incidence and severity of cough in patients undergoing abdominal surgery: A prospective, randomized, double-blind study. Current Therapeutic Research, 2008. 69(6): p. 480-487.

[2] Hung, K.C., et al., The effect of pre-emptive use of minimal dose fentanyl on fentanyl-induced coughing. Anesthesia, 2010. 65(1): p. 4-7.

[3] Liu, X., et al., Dezocine prevents sufentanil-induced cough during general anesthesia induction: A randomized controlled trial Pharmacological Reports, 2015. 67(1): p. 52-55.

[4] Agarwal, A., et al., Comparison of the incidence and severity of cough induced by sufentanil and fentanyl: a prospective, randomised, doubleblind study. Anaesthesia, 2007. 62(12): p. 1230-1232.

[5] Sun, S. and S. Huang. Effects of pretreatment with a small dose of dexmedetomidine on sufentanil-induced cough during anesthetic induction. Journal of Anesthesia, 2013. 27(1): p. 25-28.

[6] An, L.J., et al., Magnesium sulfate inhibits sufentanil-induced cough during anesthetic induction. International Journal of Clinical \& Experimental Medicine, 2015. 8(8): p. 13864-8.

[7] Mabelle C. Tannous El Baissari, S.K.T.S., Fentanyl - Induced cough PathoPhysIology and PreventIon. M.E.J. ANESTH, 2014. 22(5).

[8] Pounsford, J.C., M.J. Birch and K.B. Saunders, Effect of bronchodilators on the cough response to inhaled citric acid in normal and asthmatic subjects. Thorax, 1985. 40(9): p. 662-7.

[9] Lui, P., C. Hsing and Y. Chu, Terbutaline inhalation suppresses fentanylinduced coughing. CAN J ANAESTH, 1996. 42(12): p. 1216-9.

[10] Anil Agarwal MD, A.A.M.S. and U.S.P. Dinesh Sahu MD, Salbutamol, beclomethasone or sodium chromoglycate suppress coughing induced by iv fentanyl. CAN J ANESTH, 2003. 50(3): p. 297-300.

[11] MD, C.L., et al., General Anesthesia Intravenous lidocaine and ephedrine, but not propofol, suppress fentanyl-induced cough. CAN J ANESTH, 2004. 51(7): p. 654-659.

[12] Spina, D. and C.P, Page, Regulating cough through modulation of sensory nerve function in the airways. Pulmonary Pharmacology \& Therapeutics, 2013. 26(5): p. 486-490.

[13] Clay, E., et al., Ozone-Induced Hypertussive Responses in Rabbits and Guinea Pigs. J Pharmacol Exp Ther, 2016. 357(1): p. 73-83.

[14] Freund-Michel, V.C., et al., 2-Agonists block tussive responses in guinea pigs via an atypical cAMP-dependent pathway. European Respiratory Journal, 2010. 35(3): p. 647-654.

[15] Phua, W.T., et al., Tussive effect of a fentanyl bolus. CAN J ANAESTH, 1991. 38(3): p. 330-4.

[16] Ambesh, S.P., et al., A huffing manoeuvre, immediately before induction of anaesthesia, prevents fentanyl-induced coughing: a prospective, randomized, and controlled study. British Journal of Anaesthesia, 2009. 104(1): p. 40-43

[17] Kamei, J., et al., Fentanyl enhances the excitability of rapidly adapting receptors to cause cough via the enhancement of histamine release in the airways. Cough, 2013.9(1): p. 3.

[18] Joel A. Bennett, et al., Difficult or impossible ventilation after sufentanil-induced anesthesia is caused primarily by Vocal Cord Closure. Anesthesiology, 1997. 87(5): p. 1070-1074.

[19] $\mathrm{Yu}, \mathrm{H}$., et al., The effect of dilution and prolonged injection time on fentanyl-induced coughing. Anaesthesia, 2007. 62(9): p. 919-922.

[20] Lin, J., et al., Prolonged injection time and Light Smoking Decrease the incidence of Fentanyl-Induced Cough. Anesthesia \& Analgesia, 2005. 101(3): p. 670-674. 